\title{
Yoga Therapy in Pregnancy
}

\author{
Margarida Ferreira ${ }^{1 *}$, Mariana Saavedra ${ }^{2}$ and Paula Clara Santos ${ }^{3,4}$ \\ ${ }^{1}$ Department of Physiotherapy, North Polytechnic Institute of Health, Portugal \\ ${ }^{2}$ Physical and Rehabilitation Medicine Department, Hospital Senhora da Oliveira, Portugal \\ ${ }^{3}$ Department of Physical Therapy, Health School of Polytechnic Institute of Porto, Portugal \\ ${ }^{4}$ Research Centre in Physical Activity, University of Porto, Portugal
}

Submission: February 09, 2018; Published: February 26, 2018

*Corresponding author: Margarida Ferreira, Department of Physiotherapy, North Polytechnic Institute of Health, CESPU-Gandra, Portugal, Email: margasufer@gmail.com

\section{Introduction}

Yoga is becoming increasingly recognized and used in developed nations as a way to reach a healthier lifestyle as it as a variety of benefits: immunological, neuromuscular, psychological, and in pain control [1,2]. A possible reason for its popularity, is that yoga helps reducing stress, anxiety, depression, chronic pain syndromes (arthritis, chronic low back pain, migraine and other types of headache), and other chronic conditions such as hypertension and diabetes in adults [1]. However, there is little knowledge about the potential benefits, of yoga among the obstetric population. Additionally American College of Obstetricians and Gynecologists (ACOG) in the committee opinion entitled "Exercise during Pregnancy and the Postpartum Period"does not recognize prenatal yoga as an adequate class program in pregnancy [3]. According to ACOG, [4] exercise should be gold standard during pregnancy, to help reduce common symptoms during pregnancy such as backache, constipation, bloating, gestational diabetes, excessive weight gain and swelling. In 2002, ACOG released its latest recommendations on exercise, which encourages at least 30 minutes of moderate exercise each day on most, if not all, days of the week [3].

Pregnancy is a condition in which women undergo distinct physiological changes and increased stress and is accompanied by unique physical and psychological demands. There is a need to manage the various physical, emotional, mental, and pain symptoms that arise throughout the stages of pregnancy and labour [5]. Numerous prospective studies in both animals and humans indicate that high stress and mood disturbances during pregnancy are associated with a variety of negative maternal and infant outcomes [6,7] including low birth weight [7], preterm birth [8], spontaneous abortion [9], lower Apgar scores [10] more difficult labor and delivery [11,12], and postpartum depression [13]. However, it does not exist any prevention treatment for mood and stress symptoms in the pregnant women population [14].

Yoga is useful to reduce anxiety in pregnant women, especially during labor, and can prevent depression [15]. In addition, it can reduce systolic and diastolic pressure in 3 to $4 \mathrm{mmHg}$ [16]. There are many types of yoga practice, it typically combines stretching exercises and a variety of poses with deep breathing, relaxation (yoga sleep), and meditation [17]. Yoga breathing exercises are capable of optimizing the capacity of the lungs to attract oxygen to be absorbed by the organs including delivering more oxygen and nutrients to the fetus [17]. In addition, yoga postures stimulate heart and diaphragm work, as well as the benefit of increasing stamina and endurance, strengthening the heart muscle. Prenatal yoga movements stimulate vagal and parasympathetic nervous system being capable of suppressing the sympathetic system that inhibits the adrenal medulla to release catecholamines (epinephrine and norepinephrine) [18]. The decrease in catecholamines causes vasodilationin the kidneys and almost all visceral organs, thereby lowering blood pressure and distributed blood volume in each minute [18]. On other hand, parasympathetic activation stimulates acetylcholine (ach) decreasing the amount of its impulse, which further slows the impulse to the ventricular muscle resulting in a decrease in blood pressure [19]. Yoga is a low impact, easily modifiable and mindful activity, wich is considered a safe and sustainable activity for pregnant women.

\section{Conclusion}

The findings in all these studies, show that yoga can be a good alternative for health professional to deal with anxiety during pregnancy, and adding prenatal yoga can improve the quality of maternal and fetal health. 


\section{References}

1. Field $\mathrm{T}$ (2011) Yoga clinical research review. Complement Ther Clin Pract 17(1): 1-8.

2. Wren AA, Wright MA, Carson JW, Keefe FJ (2011) Yoga for persistent pain: new findings and directions for an ancient practice. Pain 152(3): 477-480.

3. ACOG Committee Obstetric Practice (2002) ACOG Committee opinion. Number 267, January 2002: exercise during pregnancy and the postpartum period. Obstet Gynecol 99(1): 171-173.

4. (2011) American college of obstetricians and gynecologists. Exercise during pregnancy. ACOG pamphlet.

5. Curtis K, Weinrib A, Katz J (2012) Systematic review of yoga for pregnant women: Current status and future directions. EvidenceBased Complementary and Alternative Medicine 2012(2012): 1-13.

6. Bonari L, Bennett H, Einarson A, Koren G (2004) Risks of untreated epression during pregnancy. Can Fam Physician 50: 37-39.

7. Wadhwa PD, Sandman CA, Garite TJ (2001) The neurobiology of stress in human pregnancy: implications for prematurity and development of the fetal central nervous system. Prog Brain Res 133: 131-142.

8. Alvarado R, Medina E, Aranda W (2002) The effect of psychosocial variables during pregnancy and in birth weight and gestational age of the newborn. Rev Med Chil 130(5): 561-568.

9. Boyles SH, Ness RB, Grisso JA, Markovic N, Bromberger J, et al. (2000) Life event stress and the association with spontaneous abortion in gravid women at an urban emergency department. Health Psychol 19(6): 510-514

10. Pagel MD, Smilkstein G, Regen H, Montano D (1990) Psychosocial influences on new born outcomes: a controlled prospective study. Soc Sci Med 30(5): 597-604.
11. Nielsen Forman D, Videbech P, Hedegaard M, Dalby Salvig J, Secher NJ (2000) Postpartum depression: identification of women at risk. BJOG 107(10): 1210-1217.

12. Ritter C, Hobfoll SE, Lavin J, Cameron RP, Hulsizer MR (2000) Stress, psychosocial resources, and depressive symptomatology during pregnancy in low-income, inner-city women. Health Psychol 19(6): 576-585.

13. Da Costa D, Dritsa M, Larouche J, Brender W (2000) Psychosocial predictors of labor/delivery complications and infant birth weight: a prospective multivariate study. J Psychosom Obstet Gynaecol 21(3): 137-148.

14. Flynn HA, Blow FC, Marcus SM (2006) Rates and predictors of depression treatment among pregnant women in hospital-affiliated obstetrics practices. Gen Hosp Psychiatry 28(4): 289-295.

15. Newham JJ, Wittkowski A, Hurley J, Aplin JD, Westwood M (2014) Effects of antenatal yoga on maternal anxiety and depression: a randomized controlled trial. Depress Anxiety 31(8): 631-640.

16. Hagins M, Selfe T, Innes K (2013) Effectiveness of yoga for hypertension: systematic review and meta-analysis. EvidenceBased Complementary and Alternative Medicine 2013(2013): 1-13.

17. Jiang Q Wu Z, Zhou L, Dunlop J, Chen P (2014) Effects of yoga intervention during pregnancy: a review for current status. Am J Perinatol 32(6): 503-514.

18. Nena E ( 2012) Soft prenatal yoga, pp. 18-39.

19. Lewis SL, Bucher L, Heitkemper MM, Harding MM, Kwong J, et al. (2016) Medical-surgical nursing: assessment and management of clinical problems, single volume: Elsevier Health Sciences. 